\title{
Color Light Metallography Versus Electron Microscopy for Detecting and Estimating Various Phases in a High-Strength Multiphase Steel
}

\author{
Shima Pashangeh ${ }^{1} \mathbb{D}$, Seyyed Sadegh Ghasemi Banadkouki ${ }^{1, * \mathbb{D}}$, Fatemeh Besharati ${ }^{1} \mathbb{D}$, Fatemeh Mehrabi ${ }^{1}$, \\ Mahesh Somani $^{2}$ and Jukka Kömi ${ }^{2}$ \\ 1 Department of Mining and Metallurgical Engineering, Faculty of Engineering, Yazd University, \\ Yazd 89195-741, Iran; pashangeh.a@gmail.com (S.P.); fatemebesharati98@gmail.com (F.B.); \\ fatemah_mehrabi@yahoo.com (F.M.) \\ 2 Materials and Mechanical Engineering, Centre for Advanced Steels Research, University of Oulu, \\ 90014 Oulu, Finland; mahesh.somani@oulu.fi (M.S.); jukka.komi@oulu.fi (J.K.) \\ * Correspondence: sghasemi@yazd.ac.ir
}

\section{check for}

updates

Citation: Pashangeh, S.; Ghasemi Banadkouki, S.S.; Besharati, F.;

Mehrabi, F.; Somani, M.; Kömi, J.

Color Light Metallography Versus

Electron Microscopy for Detecting and Estimating Various Phases in a High-Strength Multiphase Steel. Metals 2021, 11, 855. https://doi.org/ $10.3390 /$ met11060855

Academic Editor: George

A. Pantazopoulos

Received: 19 April 2021

Accepted: 21 May 2021

Published: 23 May 2021

Publisher's Note: MDPI stays neutral with regard to jurisdictional claims in published maps and institutional affiliations.

Copyright: (c) 2021 by the authors. Licensee MDPI, Basel, Switzerland. This article is an open access article distributed under the terms and conditions of the Creative Commons Attribution (CC BY) license (https:/ / creativecommons.org/licenses/by/ $4.0 /)$.
Abstract: In this study, fresh attempts have been made to identify and estimate the phase constituents of a high-silicon, medium carbon multiphase steel (DIN 1.5025 grade) subjected to austenitization at $900{ }^{\circ} \mathrm{C}$ for $5 \mathrm{~min}$, followed by quenching and low-temperature bainitizing (Q\&B) at $350{ }^{\circ} \mathrm{C}$ for $200 \mathrm{~s}$. Several techniques were employed using different chemical etching reagents either individually (single-step) or in combination of two or more etchants in succession (multiple-step) for conducting color metallography. The results showed that the complex multiphase microstructures comprising a fine mixture of bainite, martensite and retained austenite phase constituents were selectivity stained/tinted with good contrasting resolution, as observed via conventional light optical microscopy observations. While the carbon-enriched martensite-retained austenite (M/RA) islands were revealed as cream-colored areas by using a double-step etching technique comprising etching with $10 \%$ ammonium persulfate followed by etching with Marble's reagent, the dark gray-colored bainite packets were easily distinguishable from the brown-colored martensite regions. However, the high-carbon martensite and retained austenite in M/RA islands could be differentiated only after resorting to a triple-step etching technique comprising etching in succession with $2 \%$ nital, $10 \%$ ammonium persulfate solution and then warm Marble's reagent at $30{ }^{\circ} \mathrm{C}$. This revealed orangecolored martensite in contrast to cream-colored retained austenite in M/RA constituents, besides the presence of brown-colored martensite laths in the dark gray-colored bainitic matrix. A quadruple-step technique involving successive etching with $2 \%$ nital, $10 \%$ ammonium persulfate solution, Marble's reagent and finally Klemm's I reagent at $40{ }^{\circ} \mathrm{C}$ revealed even better contrast in comparison to the triple-step etching technique, particularly in distinguishing the RA from martensite. Observations using advanced techniques like field emission scanning electron microscopy (FE-SEM) and electron back scatter diffraction (EBSD) failed to differentiate untempered, high-carbon martensite from retained austenite in the M/RA islands and martensite laths from bainitic matrix, respectively. Transmission electron microscopy (TEM) studies successfully distinguished the RA from high-carbon martensite, as noticed in M/RA islands. The volume fraction of retained austenite estimated by EBSD, XRD and a point counting method on color micrographs of quadruple-step etched samples showed good agreement.

Keywords: advanced high-strength steel; color metallography; multiphase microstructure; bainite; martensite; retained austenite

\section{Introduction}

In recent years, the design and development of a new class of multiphase highstrength steels containing small fractions of finely divided, carbon-enriched austenite led 
to the emergence of novel engineering materials belonging to the 3rd generation advanced high-strength steels (AHSSs) [1,2]. Innovative processing routes, such as quenching and partitioning (Q\&P) and low-temperature transformation for ultrafine/nanostructured bainite, have since been proposed as the potential means of improving the balance of elongation to fracture and tensile strength for these 3rd generation steels $[3,4]$. Unlike in the case of tempering, the formation of iron carbides is intentionally suppressed in these multiphase steels by suitably alloying with high silicon and/or aluminum to suppress the formation of iron carbides and to stabilize a fraction of finely divided austenite down to room temperature. To impart ultrafine bainitic structures in these multiphase steels with the possibility of achieving good strength-ductility combinations and adequate toughness, the steel samples are first austenitized and then subjected to isothermal heat treatments at a temperature close to the martensite start temperature $\left(\mathrm{M}_{\mathrm{S}}\right)$ [5]. During isothermal holding, the decomposition of austenite into (ultra)fine bainite occurs continuously with a concomitant partitioning of carbon to the adjacent austenite grains and the extent of carbon diffusion and its equilibration in austenite will depend on the kinetics of bainite formation. During final cooling, a part of untransformed austenite decomposes into untempered high-carbon martensite, thus stabilizing a significant fraction of finely divided retained austenite (RA) at room temperature (RT). This results in a very fine, complex multiphase microstructure with various phase constituents [6]. In the microstructures of these multiphase AHSSs, the RA phase can be seen as blocky pools and/or thin films between the bainitic and/or martensitic laths. These blocky pools/islands often appear as a mixture of both martensite $(\mathrm{M})$ and RA microconstituents called M-RA islands [7,8]. The thermal stability of the retained austenite is related to the isothermal holding conditions, and the extent of carbon partitioning from bainite and/or martensite to the adjacent untransformed austenite films/grains prior to cooling at RT [9,10].

Both the qualitative and quantitative characterization of these multiphase microstructures, particularly in respect to retained austenite, its stability, size, shape, distribution, morphology, carbon content, etc., help in optimizing the processing conditions in order to achieve a given set of mechanical properties, i.e., tensile (UTS) and yield (YS) strengths, besides ductility $[5,11]$. Of course, RA phase is the main factor affecting mechanical properties through the well-known transformation-induced plasticity (TRIP) effect $[5,12]$. The volume fraction of RA could have both positive and negative consequences on the final engineering properties of AHSSs [6].

For several years, color light metallography has been used to enhance the visual identification of various phase constituents to characterize the microstructures [13]. Additionally, it is an easy, quick and inexpensive method to be able to reveal and discern several microphases, particularly if they are fine and complex [14]. Although color light metallography is a recognized etching technique to identify multiphase microstructures, it has its own limitations as well. For example, the technique is not very versatile and can vary significantly for a given composition depending on the type of structure and its etching response and often relies on the expertise and experience of a metallographer to get the best contrasting resolution between different phase constituents [15]. Sometimes it is necessary to use several tint etching reagents separately or in succession to provide good contrast between different phases of the complex microstructures [14,16,17]. In recent years, many attempts have been made to conduct color metallography of the RA phase, but most of these attempts have failed $[13,18,19]$. In general, detection and estimation of fine RA phase in the presence of other phases and selective coloration of a particular microconstituent in a complex microstructure continue to be difficult and challenging $[18,20]$.

It is well established that the etching methods are different and complex depending on the steel's chemical composition and microstructural components [13,18]. Accordingly, the extent of bainite, martensite and RA phases present in the microstructures of AHSSs renders their discernment difficult, although the use of color metallography is capable of identifying even very finely divided phases with high contrast by employing a special etching technique described by Vander and Walker et al. [21,22]. Although Vander Voort et al. [18] 
suggested that the addition of $1 \%$ zephiran chloride to $4 \%$ nital was useful to detect RA phase with a high resolution in a martensite-austenite structure, this reagent did not color the fine RA. Additionally, using other tint etching reagents, such as $10 \%$ sodium metabisulfate and Beraha's sulfamic acid, could color the microstructures, but could not, however, distinguish the RA phase from other phases. Girault et al. [23] used LePera's tint etching solution to identify the four phases of the microstructures of TRIP-assisted steels. This tint etching solution could have been useful to color and reveal the different phases, but there was a limitation in the detection of RA phase from martensite. Mehranfar et al. [16] developed a new double-step color metallography technique, using an etching solution of $10 \%$ ammonium persulfate and Glyceregia to color and distinguish the RA and martensite phases from other phase constituents in a low alloy white cast iron. Various techniques are still underway with little or no success, and sometimes presenting conflicting reports regarding the microstructural characterization of bainite, martensite and retained austenite multiphase microstructures. For these reasons, the purpose of this investigation is to develop a method to designate various phases characterizing the microstructural features of a high-silicon, medium-carbon steel sample, austenitized and quenched to $350{ }^{\circ} \mathrm{C}$, a temperature in the lower bainite range slightly above the $\mathrm{M}_{\mathrm{S}}$ temperature $\left(275^{\circ} \mathrm{C}\right)$, and held isothermally for $200 \mathrm{~s}$ in order to facilitate bainitic transformation. The sample was named the Q\&B specimen based on the applied thermal treatment comprising quenching and bainitic holding. This was followed by different etching techniques for color metallography using a light optical microscope. In addition, detailed microstructural analysis was carried out using a TEM and an FE-SEM equipped with an EBSD facility, and was further supported by XRD analyses to detect and estimate the bainitic/martensitic ferrite and RA phase fractions in the Q\&B sample. Another objective of this investigation is to highlight various merits of light color metallography in identifying every single-phase constituent with good contrasting resolution in comparison to the detection and estimation using advanced characterization techniques, e.g., FE-SEM, EBSD, TEM and XRD.

\section{Materials and Methods}

In this study, the investigations were carried out on a DIN1.5025 steel sheet (1mm thickness) sample with the chemical composition presented in Table 1. A suitable Q\&B heat treatment process schedule was designed to achieve the multiphase microstructure with different percentages of bainite, martensite and RA phases. For this purpose, the determination of critical temperatures such as $A c_{1}, A_{3}$ and $M_{S}$ was considered essential. Consequently, the critical temperatures for this steel sheet sample were determined by conducting dilatometer measurements in a Gleeble 3800 thermomechanical simulator with heating and cooling held at linear rates of 0.2 and $150{ }^{\circ} \mathrm{C} / \mathrm{s}$, respectively. The corresponding temperatures were estimated as 765,835 and $275^{\circ} \mathrm{C}$, for $\mathrm{Ac}_{1}, \mathrm{Ac}_{3}$ and $\mathrm{M}_{\mathrm{s}}$ temperatures, respectively. The bainite start $\left(\mathrm{B}_{\mathrm{S}}\right)$ temperature was estimated to be about $471^{\circ} \mathrm{C}$ using an empirical equation given by $\mathrm{Li}$ [24]. A schematic of the two-step quenching and bainitic holding (Q\&B) heat treatment cycle is depicted in Figure 1. In the first step, the specimens were heated at $900{ }^{\circ} \mathrm{C}$ and held for $5 \mathrm{~min}$, followed by air cooling (normalizing step). In the second step, the specimens were reaustenitized at $900{ }^{\circ} \mathrm{C}$ for $5 \mathrm{~min}$, quenched in a salt bath maintained at $350{ }^{\circ} \mathrm{C}$, held for $200 \mathrm{~s}$ for bainitic transformation and then quenched in water to ambient temperature [6].

Table 1. Chemical composition of DIN1.5025 steel sheet.

\begin{tabular}{cccccccc}
\hline Alloying Elements & $\mathbf{C}$ & $\mathbf{M n}$ & $\mathbf{S i}$ & $\mathbf{C r}$ & $\mathbf{S}$ & $\mathbf{P}$ & $\mathbf{F e}$ \\
\hline wt. $\%$ & 0.529 & 0.721 & 1.670 & 0.120 & 0.023 & 0.022 & Balance \\
\hline
\end{tabular}




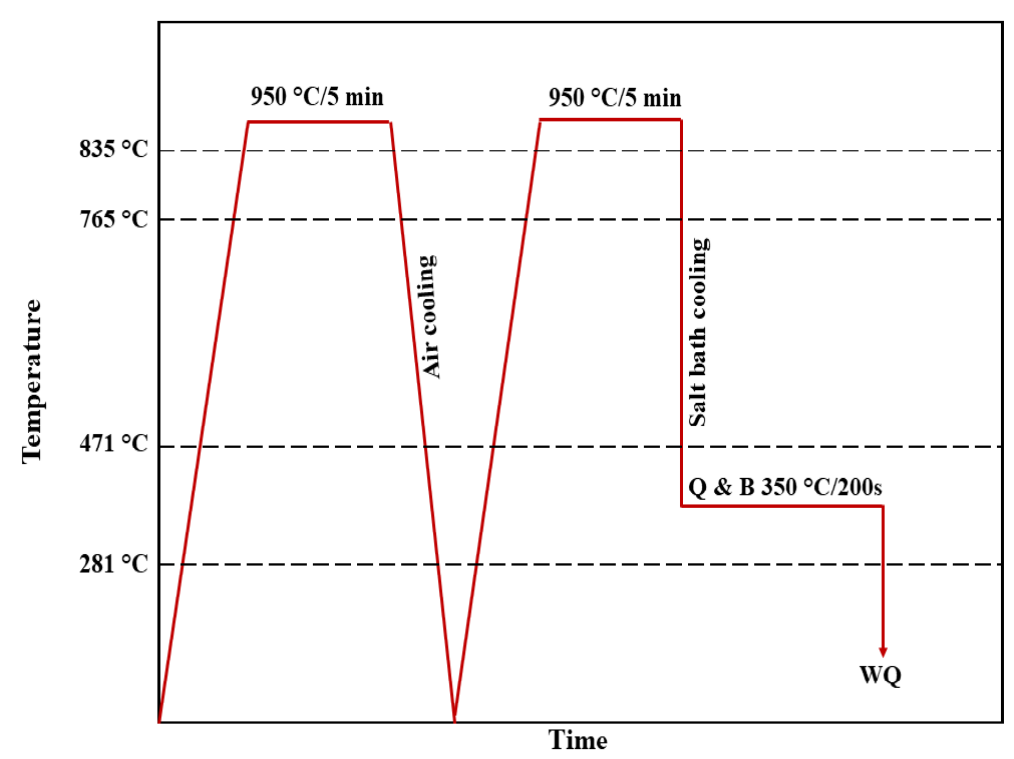

Figure 1. The schematic diagram of quenching and low temperature bainitizing $(\mathrm{Q} \& \mathrm{~B})$ heat treatment schedule used in this study.

After the samples were heat treated according to the Q\&B schedule, the samples were cold mounted, ground and finally polished to a high quality in accordance with the standard ASTM E3 $[15,25]$. In order to carry out the microstructural observations, color metallography was done with various tint etching solutions, as listed in Table 2. Additionally, the samples were etched in single, double, triple and quadruple steps using a combination of etching reagents in succession, as illustrated in Table 3 , for different holding times at various temperatures according to the optimal conditions depending on the etching reagents in order to detect a specific phase or phases with a good contrasting resolution. The color metallographic observations were made with an OLYMPUS PMG3, Olympus, Tokyo, Japan light microscope. ImageJ, ImageJ developers, Maryland, USA analyzing software was used to analyze the phase constituents recorded on optical micrographs and the volume fractions of different phases were estimated according to the ASTM E562 [26] standard using at least five representative areas of $200 \times 200 \mu \mathrm{m}^{2}$ at different locations of the samples. In all cases, the average values have been reported.

Table 2. Various tint etching reagents used in this research work.

\begin{tabular}{|c|c|c|c|}
\hline Etching Reagent & Chemical Composition & Purpose & Ref. \\
\hline $2 \%$ nital & $2 \mathrm{~mL} \mathrm{HNO}_{3}, 98 \mathrm{~mL}$ ethanol & reveals the phase boundaries & [11] \\
\hline Vilella's & $1 \mathrm{~g}$ picric acid, $5 \mathrm{~mL} \mathrm{HCl}, 100 \mathrm{~mL}$ ethanol & reveals the RA grains & [13] \\
\hline Marble's reagent & $5 \mathrm{~g} \mathrm{CuSO}_{4}, 16 \mathrm{~mL} \mathrm{HCl}, 30 \mathrm{~mL}$ ethanol & colors bainite plates & [11] \\
\hline $10 \%$ ammonium persulfate & $10 \mathrm{~g}\left(\mathrm{NH}_{4}\right)_{2} \mathrm{~S}_{2} \mathrm{O}_{8}, 100 \mathrm{~mL}$ distilled water & attacks the RA and matrix & [21] \\
\hline Klemm's I & $1 \mathrm{~g} \mathrm{~K}_{2} \mathrm{~S}_{2} \mathrm{O}_{5}$ in $50 \mathrm{ml} \mathrm{Na} \mathrm{S}_{2} \mathrm{O}_{3}$ aqueous solution & colors martensite & [21] \\
\hline
\end{tabular}

In addition, microstructural details were examined using a TESCAN MIRA3 FE-SEM (Tescan, Brno, Czech Republic) and a $200 \mathrm{kV}$ Jeol JEM-2200FS STEM, and the volume fractions of RA phase were measured by performing XRD analysis [27] on a Rigaku SmartLab $9 \mathrm{~kW}$ XRD, using a Co-K $\alpha$ radiation source operated at $135 \mathrm{~mA}$ and $40 \mathrm{kV}$ with $2 \theta$ ranging between 45 and $130^{\circ}$ and the rotation performed at $7.2^{\circ} / \mathrm{min}$. Rietveld whole powder pattern fitting (WPPF) analysis was used for quantitative investigation of RA. The volume fraction of RA was measured using a direct comparison approach, comparing the integrated intensities of (111), (200), (220) and (311) of FCC diffracted planes with (101), (002), (112) and (202) of BCC planes, respectively. Additionally, an EBSD facility (Physical Electronics Company, Chanhassen, MN, USA), equipped with the FE-SEM, was 
used to detect and image different phase constituents using a scanning auger nanoprobe (Physical Electronics-PHI 710 EBSD system). The operating conditions of EBSD are as follows: acceleration voltage $15 \mathrm{kV}$, working distance $8 \mathrm{~mm}$, beam current $10 \mathrm{nA}$, tilt angle $70^{\circ}$, scanned area $50 \times 50 \mu \mathrm{m}^{2}$ with a scanning step size of $150 \mathrm{~nm}$. TSL OIM7.3, EDAX, Mahwah, NJ, USA software was used later to analyze the EBSD data [6].

Table 3. Color metallography methods based on various etching techniques.

\begin{tabular}{|c|c|}
\hline Test Method & Etching Reagent \\
\hline Single-step & $\begin{array}{l}\text { i. } 2 \% \text { nital }(10-15 \mathrm{~s}) \\
\left.\text { ii. Marble's reagent at room temperature (about } 20^{\circ} \mathrm{C}\right)(5-10 \mathrm{~s}) \\
\text { iii. Vilella's solution }(15-20 \mathrm{~s})\end{array}$ \\
\hline Double-step & $\begin{array}{l}\text { i. First etched in } 10 \% \text { ammonium persulfate solution }(8-12 \mathrm{~s}) \text {, followed by etching in Marble's reagent } \\
\left.\text { at room temperature (about } 20^{\circ} \mathrm{C}\right)(5-7 \mathrm{~s}) \text {. } \\
\text { ii. First etched in } 10 \% \text { ammonium persulfate solution }(8-12 \mathrm{~s}) \text {, followed by etching in Marble's } \\
\text { reagent at } 30^{\circ} \mathrm{C}(4-6 \mathrm{~s}) .\end{array}$ \\
\hline Triple-step & $\begin{array}{l}\text { First etched in } 2 \% \text { nital (5-8 s), followed by etching in } 10 \% \text { ammonium persulfate solution }(4-8 \mathrm{~s}) \text { and } \\
\text { then final etching in Marble's reagent at } 30^{\circ} \mathrm{C}(4-6 \mathrm{~s}) \text {. }\end{array}$ \\
\hline Quadruple-step & $\begin{array}{c}\text { First etched in } 2 \% \text { nital }(5-8 \mathrm{~s}) \text {, then in } 10 \% \text { ammonium persulfate solution }(4-8 \mathrm{~s}) \text {, followed by } \\
\left.\text { etching in Marble's reagent at room temperature (about } 20^{\circ} \mathrm{C}\right)(5-10 \mathrm{~s}) \text { and final etching in Klemm's I } \\
\text { reagent at } 40^{\circ} \mathrm{C}(3-5 \mathrm{~s}) .\end{array}$ \\
\hline
\end{tabular}

\section{Results and Discussion}

\subsection{Optical Micrography}

\subsubsection{General Single-Step Metallography}

Different single-step and multiple-step (Table 3) color metallography techniques have been used based on techniques involving various chemical etching reagents [21,22], as listed in Table 2. Due to the development of a very fine mixture of bainite, martensite and retained austenite in the multiphase microstructure, high-magnification light optical microscopy was used. Figure $2 \mathrm{a}-\mathrm{C}$ show the optical micrographs of Q\&B samples at the highest possible magnification, taken after etching with different reagents, viz., $2 \%$ nital, Vilella's and Marble's reagents, respectively. As can be seen from Figure 2, the three etchants individually were unable to differentiate every microconstituent, such as bainite, martensite and RA with good contrasting resolution, whereas, by using $\%$ nital and Marble's reagents, the martensite/retained austenite $(\mathrm{M} / \mathrm{RA})$ islands appeared as white-colored constituents (marked with arrows in Figure 2a,c, respectively) and bainite plates appeared as dark gray constituents, while Vilella's reagent was ineffective in detecting the RA phase in this microstructure, though it is widely used to identify this phase. Additionally, M/RA islands could not be clearly characterized and distinguished from martensite phase (Figure $2 b$ ) and only bainite was partly revealed, appearing as dark gray-colored constituents in the final microstructural observation. These results clearly indicate that these single-step general etching techniques with $2 \%$ nital, Marble's reagent and Vilella's reagent are not useful in detecting different phases with a clear distinction from each other in complex, multiphase steel microstructures. Hence, in this study, several new multiple-step etching techniques were considered for identifying various phases of the multiphase microstructures of these Q\&B samples with high contrasting resolution. Therefore, different multiple-step etching processes will now be discussed which have been used to develop a good contrast between different phase constituents of the $Q \& B$ heat treated samples with complex microstructures. 

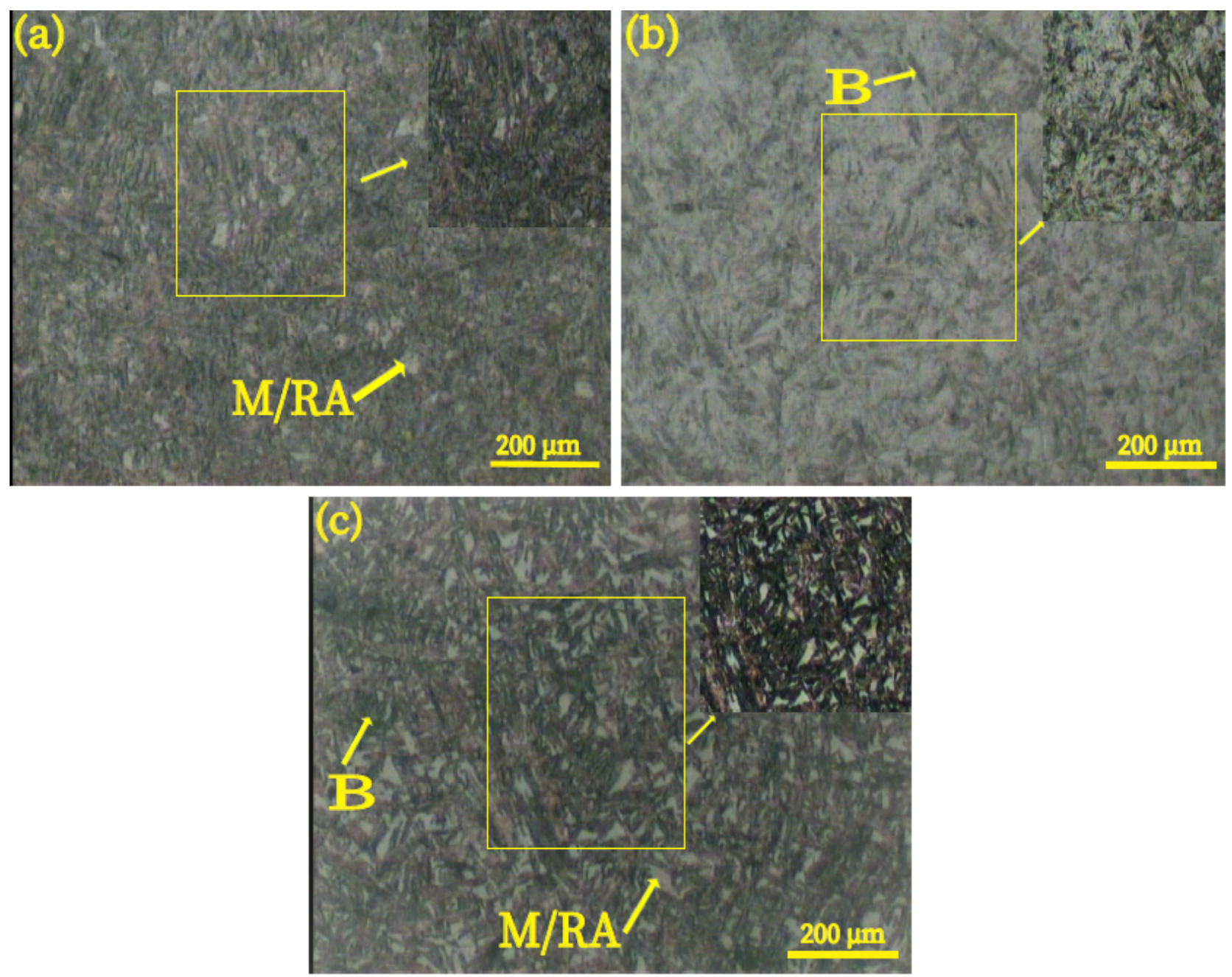

Figure 2. Optical micrographs of Q\&B specimens etched in (a) 2\% nital; (b) Vilella's; and (c) Marble's etching reagents. The bainite (B) and martensite/retained austenite islands (M/RA) are indicated with arrows.

\subsubsection{Double-Step Metallography}

Figure 3a shows the high-magnification light microstructural image of the $Q \& B$ heat treated sample etched in two successive steps, first by immersion in 10\% ammonium persulfate and then in Marble's reagent, termed as double-step I, as listed in Table 3. During and after every step of double-step I etching, the sample was carefully cleaned and dried as per the standard metallographic practice. While the ammonium persulfate solution etched the matrix and M/RA islands [28,29], the Marble's reagent subsequently attacked bainite plates [29]. Therefore, the carbon-enriched M/RA islands, appearing as cream-colored bright areas, became discernible and easily distinguishable from brown-colored martensite and dark gray-colored bainite plates, as indicated by arrows in Figure 3, and whereas the dark gray bainite plates and brown-colored martensite are easily identifiable from each other, the $\mathrm{M}$ and RA microconstituents of $\mathrm{M} / \mathrm{RA}$ islands are not easily distinguishable from each other in the micrograph, as more clearly shown in the enlarged Figure $3 b$. All the same, this etching method can be considered to be more useful for detecting different phase constituents in the complex, multiphase microstructures in comparison to general single-step etching techniques (Figure 2). However, this technique does not make a clear contrasting resolution between the components of the M/RA dispersed islands, i.e., martensite and RA. For this reason, another double-step etching method was tried to develop a good contrast between these two finely divided phase constituents. 


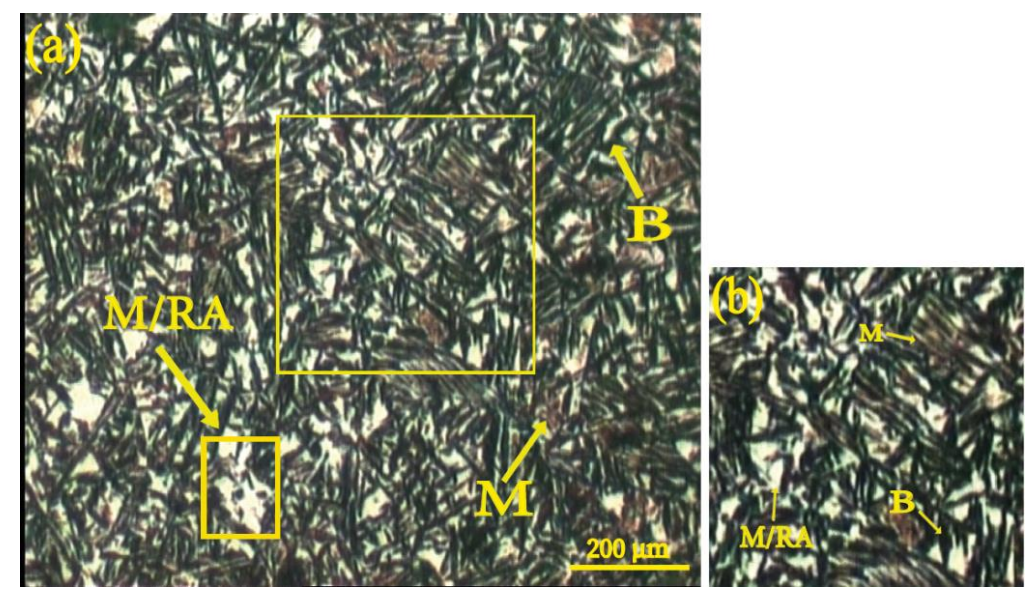

Figure 3. (a) Double-step I etching method (10\% ammonium persulfate solution + Marble's reagent). (b) Enlarged image view of the square shown in (a). The abbreviations B, M and M/RA represent bainite, martensite and martensite/retained austenite phase constituents, respectively.

The double-step II etching technique was very similar to double-step I (Table 3), as the sample was first etched in the $10 \%$ ammonium persulfate solution, followed by etching in Marble's reagent with its temperature raised to $30^{\circ} \mathrm{C}$. As the temperature of Marble's reagent was increased, its etching characteristics changed too, with enhanced sensitivity, and it was capable of tinting the martensite. The phase constituents, viz., bainite (dark gray), martensite (brown) and M/RA (cream), were revealed with a better contrasting resolution, as indicated with arrows in Figure 4 a. While the ammonium persulfate solution etched the matrix and M/RA phases, Marble's reagent heated at $30^{\circ} \mathrm{C}$ color-tinted the bainite plates with better contrast [28,30]. Moreover, a better contrasting resolution has been achieved, identifying different phase constituents in comparison to the single-step etching (either with $2 \%$ nital or Marble's or Vilella's etchant; Figure 2), in addition to the double-step I technique (Figure 3). Although this double-step II etching technique with Marble's reagent heated at $30^{\circ} \mathrm{C}$ is better than the double-step I etching technique, it has the limitation of developing a reasonably good contrast between carbon-enriched fine martensite laths and RA in cream-colored M/RA islands (Figure $4 \mathrm{~b}$ ). Therefore, further work was carried out to develop the triple- and quadruple-step etching techniques to differentiate various phase constituents in the microstructures.
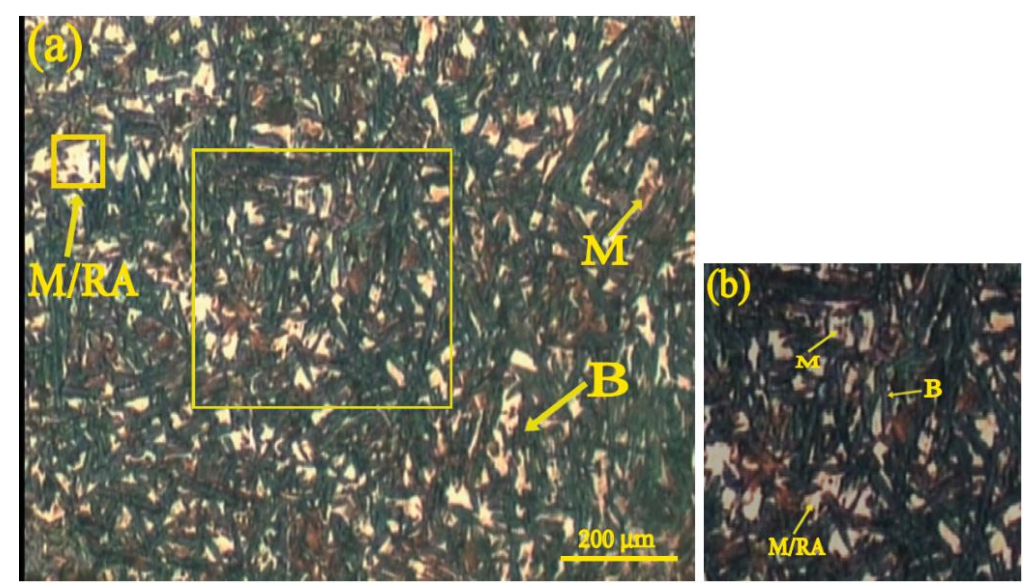

Figure 4. (a) Double-step II etching method (10\% ammonium persulfate solution + warm Marble's reagent at $\left.30{ }^{\circ} \mathrm{C}\right)$. (b) Enlarged image view of the square shown in (a). The abbreviations B, M and $\mathrm{M} / \mathrm{RA}$ represent bainite, martensite and martensite/retained austenite phase constituents, respectively. 


\subsubsection{Triple-Step Metallography}

Figure $5 \mathrm{a}$ is a typical light micrograph of the Q\&B heat treated sample color etched using the triple-step method, as listed in Table 3. The chemical reagents used for etching in succession are: a) $2 \%$ nital, b) $10 \%$ ammonium persulfate and c) Marble's reagent at $30{ }^{\circ} \mathrm{C}$ (Table 3). The sample was carefully cleaned and dried after each step of etching. In this technique, the complex phase mixture of bainite and martensite appears much sharper as dark gray- and brown-colored packets/laths, respectively, as shown in Figure 5a. Moreover, the constituents of M/RA islands can be easily differentiated from each other, with RA particles appearing as cream-colored fine grains, speckled with fine, orange-colored, carbonenriched martensite laths (clearly shown in Figure $5 b$ ). In this method, etching with $2 \%$ nital solution revealed the interphase boundaries between martensite and bainite plates, but left the untempered, high-carbon martensite and RA constituents of M/RA phase unattacked. During the second step, etching with $10 \%$ ammonium persulfate solution attacked the high-carbon martensite of M/RA islands as orange-colored laths. Finally, Marble's reagent tinted the bainite as a dark gray-colored phase constituent. These observations indicate that this metallography technique leads to better identification of finely divided high-carbon martensite from RA in the M/RA constituents [21]. It is observed that the use of $2 \%$ nital renders the color of bainite a dark gray (instead of gray) and that of RA as shiny white (instead of cream colored). A quick comparison of the etching techniques discussed so far (Figures 2-5) suggests that the triple-step etching technique is a very useful method for distinguishing the carbon-enriched martensite from RA and producing a sharp contrast, particularly between bainite and martensite in the multiphase microstructures.

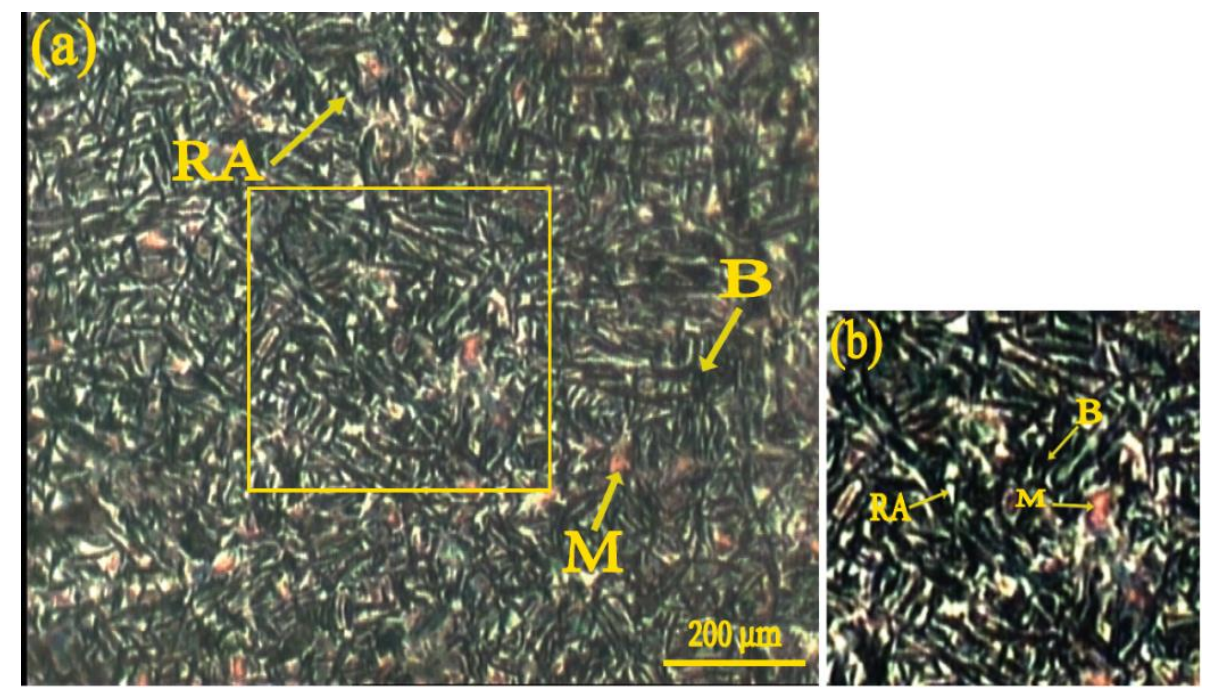

Figure 5. (a) Triple-step etching method ( $2 \%$ nital $+10 \%$ ammonium persulfate solution + warm Marble's reagent at $30^{\circ} \mathrm{C}$ ). (b) Enlarged image view of the square shown in (a). The abbreviations B, $\mathrm{M}$ and RA represent bainite, martensite and retained austenite phase constituents, respectively.

\subsubsection{Quadruple-Step Metallography}

The quadruple-step etching technique is based on etching with different reagents in succession, i.e., $2 \%$ nital, $10 \%$ ammonium persulfate, Marble's reagent and, finally, warm Klemm's I reagent heated at $40{ }^{\circ} \mathrm{C}$. The sample was carefully cleaned and dried after each step of etching. As shown in Figure 6a, after the quadruple-step etching, the RA phase, lath martensite and bainite phase appear as cream-colored, brown and dark gray, respectively, indicated by arrows in the figure. The $2 \%$ nital solution was used to develop the phase boundary contrast, whereas Klemm's I reagent $\left(\mathrm{at} 40^{\circ} \mathrm{C}\right)$ helped in the coloration of martensite [21]. Therefore, this etching technique also produces an excellent contrasting resolution of various phases in a complex mixture of bainite plates (dark gray), martensite laths (brown) and finely divided retained austenite (cream-colored), so that the amount of 
RA phase can be approximately estimated (Figure 6b), though limited by the resolution of the light optical microscopy.

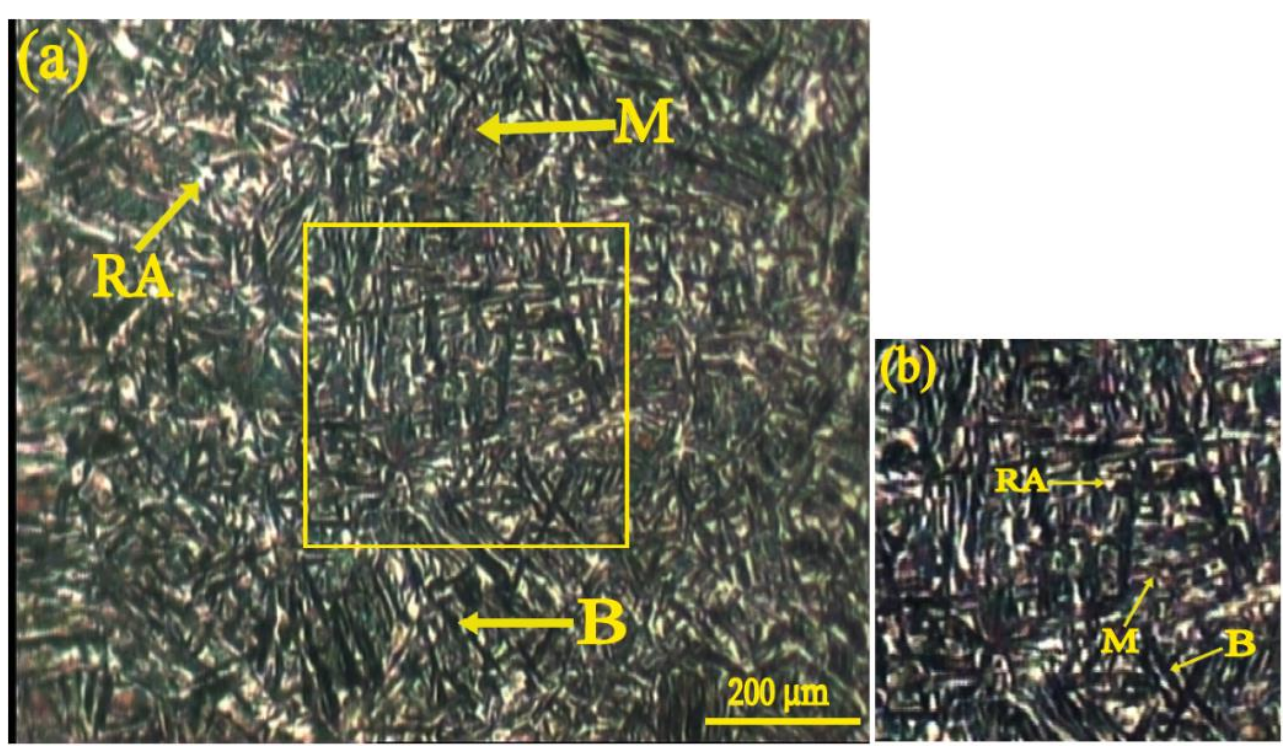

Figure 6. (a) Quadruple-step etching technique (2\% nital + 10\% ammonium persulfate + Marble's reagent + Klemm's I solution at $40^{\circ} \mathrm{C}$ ). (b) Enlarged image view of the square shown in (a). The abbreviations B, M and RA represent bainite, martensite and retained austenite phase constituents, respectively.

\subsection{Microstructural Characterization With FE-SEM, EBSD, TEM and XRD Techniques}

To confirm the reliability of color light metallography results, the microstructural observations were carried out with an FE-SEM combined with EBSD, and further aided with XRD measurements. Figure 7 shows a typical backscattered electron (BSE) micrograph of the $\mathrm{Q} \& \mathrm{~B}$ heat treated sample, characterized with many islands of M/RA constituents, present in a relatively featureless martensitic matrix, in a manner similar to that of the general features noticed in the single-step light optical metallograph (see Figure 2). It can be observed that the use of the FE-SEM technique did not differentiate RA from the highcarbon martensite, present as M/RA islands in the microstructure. Since the martensite and RA had an almost similar chemical composition, it is possible that these phase constituents cannot be differentiated in the BSE imaging because of the similar composition contrast, appearing as gray islands [1]. Bainite phase could also be discerned, but the volume fraction of RA could not be estimated using FE-SEM examination [6].

Typical examples of TEM micrographs including both bright (BF) and dark field (DF) images and diffraction pattern analysis for the heat treated samples are presented in Figure 8. It can be seen that the Q\&B specimens isothermally held at $350^{\circ} \mathrm{C}$ for $200 \mathrm{~s}$ contained M/RA islands in a relatively featureless bainite/martensite matrix. The DF image (Figure $8 \mathrm{~b}$ ) clearly reveals the presence of finely divided retained austenite. However, this information is obtained from local areas and does not include the inhomogeneity of the phase composition of the Q\&B heat treated sample. As TEM images are taken locally, it is hard to determine the volume fractions of different phases due to the presence of inhomogeneity in the microstructure of the heat treated sample. However, it is a very powerful technique to investigate the multiphase microstructure and identify different microconstituents. 


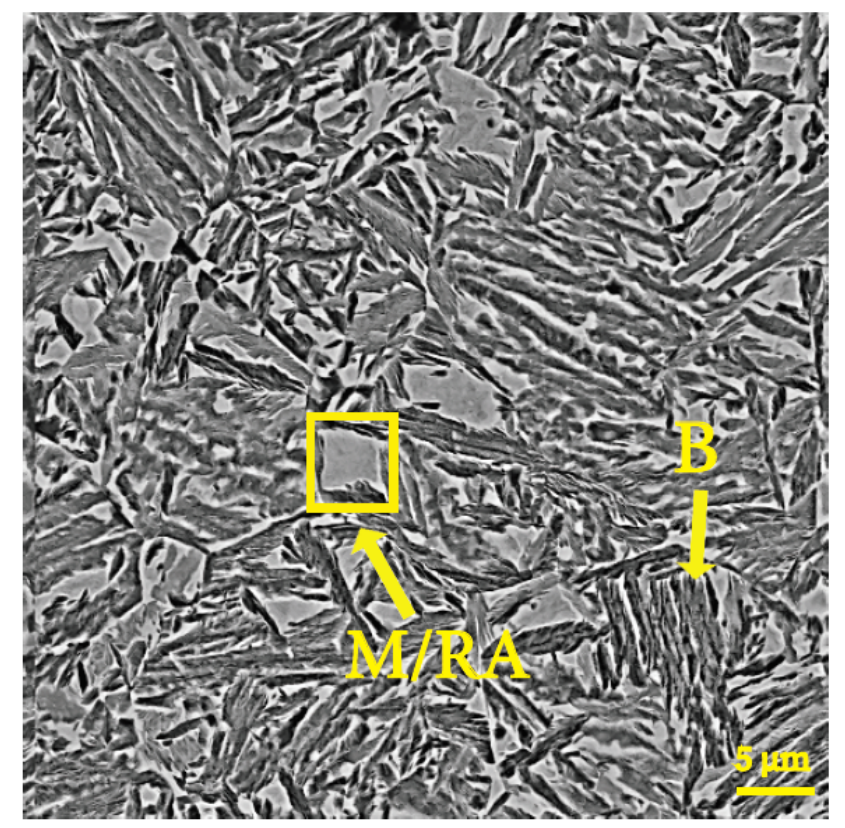

Figure 7. A field emission scanning electron microscopy-backscattered electron (FE-SEM BSE) micrograph of the Q\&B specimen held in the molten salt bath at $350{ }^{\circ} \mathrm{C}$ for $200 \mathrm{~s}$, followed by water cooling to the ambient temperature. The abbreviations $B$ and M/RA represent bainite and martensite/retained austenite phase constituents, respectively.
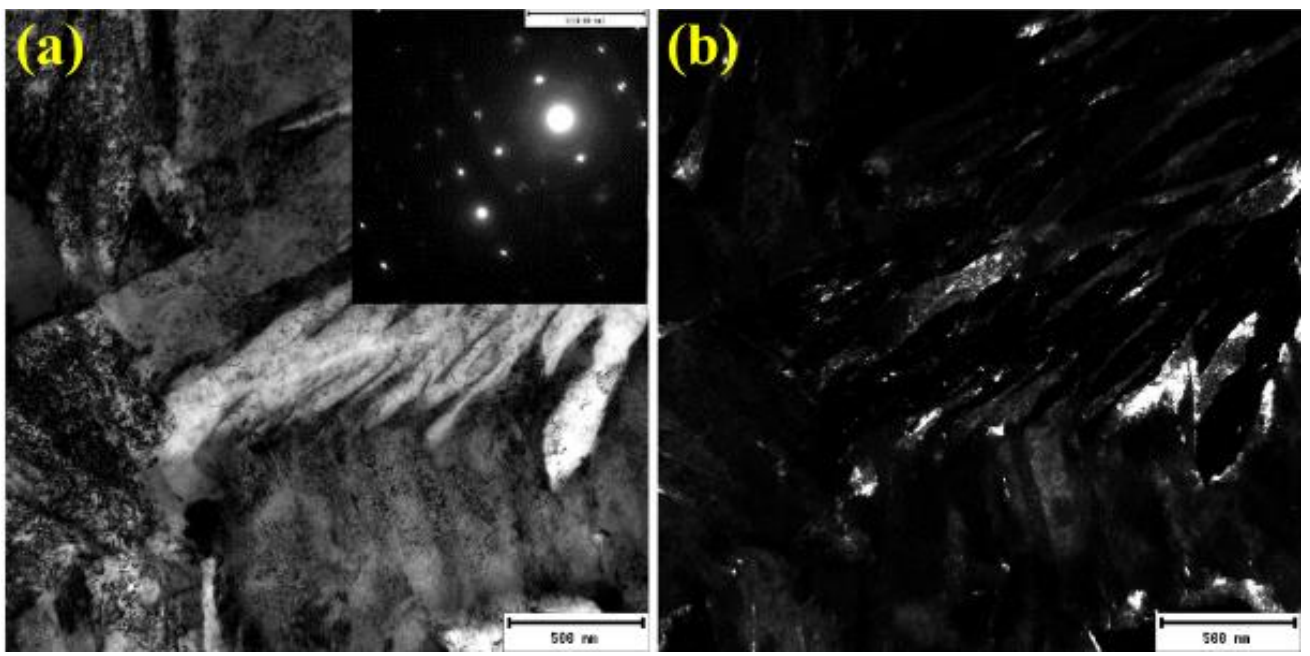

Figure 8. Transmission electron microscopy (TEM) images of $Q \& B$ heat treated sample. (a) Bright field (BF) image, (b) dark field (DF) micrograph using a $\{111\}$ diffracted retained austenite phase. The selected area electron diffraction (SAED) pattern is shown as an inset in the corresponding BF image.

The EBSD combined with FE-SEM is a very useful supplementary technique to provide crystallographic features of multiphase microstructures through phase contrast imaging [30]. The possibility of rapid analysis with relatively high resolution, lattice parameter determination and quantification of microstructures are some of the positive aspects of EBSD analysis [11]. In the EBSD micrograph presented in Figure 9a, the green-colored RA phase (FCC-lattice; an area depicted at high magnification in Figure 9b), is distributed between red-colored bainite (matrix) and/or martensite phase constituents (BCC-lattice), as can also be identified on the basis of their morphological characteristics [31]. Additionally, the EBSD phase maps were used to measure the volume fraction of RA phase [32], although such estimation can be easily limited by the resolution of the EBSD (about $0.08 \mu \mathrm{m}$ ) and the corresponding result is included in Table 4. 

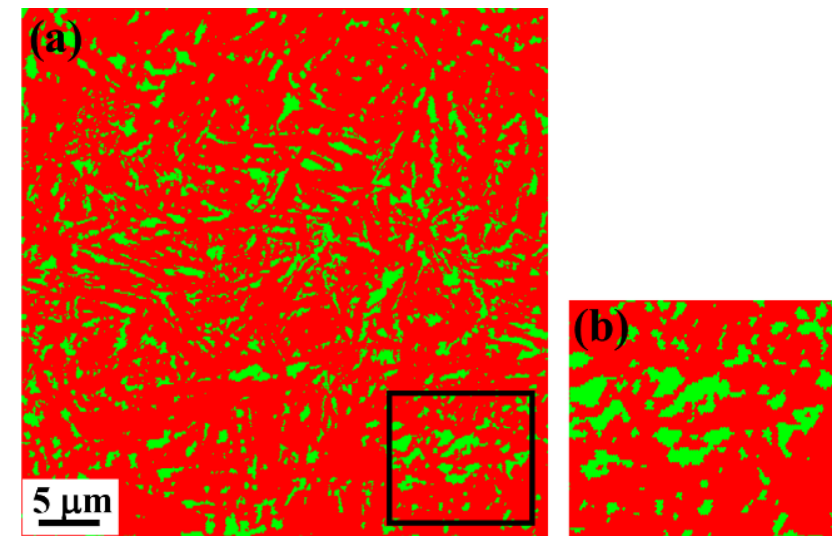

Figure 9. (a) EBSD phase map showing the green-colored RA (FCC) islands in the red-colored bainitic ferrite matrix with martensite packets (BCC). (b) Enlarged phase map view of the rectangle shown in (a).

For further confirmation of color light metallography observations, the analysis of the XRD measurements conducted on the Q\&B sample is presented in Figure 10. The $\mathrm{XRD}$ pattern clearly reveals that the heat treated sample is a multicrystalline structure comprising the BCC (bainite and/or martensite (B/M)) and FCC (RA) phase constituents. The intensity peaks of (111), (200), (220) and (311) diffracted planes correspond to the FCC RA phase ( $2 \theta$ angles of $51^{\circ}, 60^{\circ}, 90^{\circ}$ and $112^{\circ}$, respectively), while the intensity peaks of (101), (002), (112) and (202) diffracted planes correspond to the BCC bainite/martensite ( $2 \theta$ angles of $52.5^{\circ}, 77^{\circ}, 100^{\circ}$ and $124^{\circ}$, respectively) phase constituents. Diffraction peaks related to carbide precipitation in bainite or martensite, if any, are not detected in the XRD patterns [6].

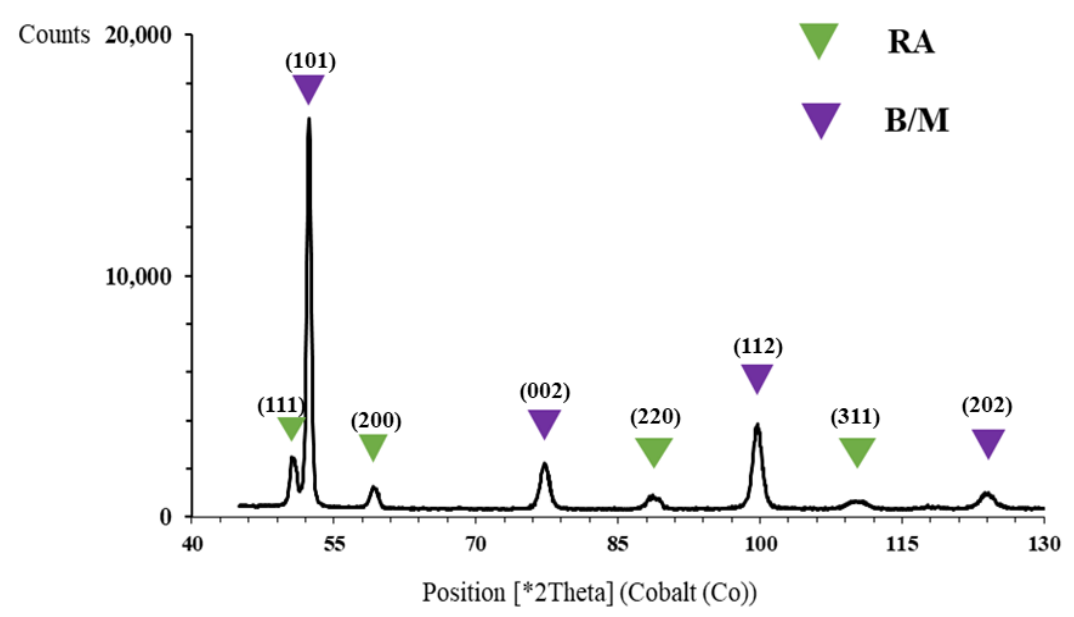

Figure 10. The X-ray diffraction (XRD) pattern of the Q\&B specimen. The intensity peaks of FCC RA are shown with green symbols, while the intensity peaks of BCC bainite/martensite (B/M) are shown with purple symbols.

\subsection{Color Light Metallography vs. Electron Microscopy}

The volume fraction of RA phase was measured by different techniques, viz., color light microscopy, EBSD and XRD analyses, and the data are listed in Table 4 along with volume fractions of other phases, i.e., bainite (matrix) and high-carbon martensite. The estimated RA volume fraction using the XRD analysis $[12,13,15,33]$ is considered reliable and is higher than the fractions estimated by optical microscopy and EBSD techniques, because of the resolution limits of the two techniques, i.e., 0.2 and $0.08 \mu \mathrm{m}$, respectively, as RA particles finer than these sizes cannot be detected by the respective techniques [6]. A comparison of the achieved volume fractions (in vol.\%) of RA phase using light color metallography methods (triple-step and quadruple-step) estimated by ImageJ software 
is shown in Figure 11, and the corresponding fractions are 12.8\% (triple-step) and 13.4\% (quadruple-step) in comparison to the estimated fractions of 15.3 and 18\%, measured by EBSD and XRD analyses, respectively. These results indicate that the quadruple-step metallography method is able to reveal a large fraction of RA phase, differentiated from the martensite and bainite phase constituents. Hence, the volume fraction of RA phase estimated by light image analysis using color metallography can be very close to the data obtained by XRD and EBSD analyses, provided an appropriate etching method is used (here, the quadruple-step method). Hence, it is interesting to point out that all the phase constituents observed in the complex microstructure of the Q\&B heat treated sample can be identified by color light metallography methods with a good contrasting resolution, even though not all of them are detectable using the advanced techniques of FE-SEM, EBSD and XRD analyses. The high-carbon martensite and retained austenite in M/RA phases show a similar composition contrast in FE-SEM observation. The EBSD analysis, on the other hand, failed to differentiate bainite plates from martensite areas in a way similar to the XRD results. Therefore, these color etching techniques are very useful in detecting various phase constituents (bainite, martensite and RA), besides estimating their volume fraction in a relatively simple and inexpensive manner, though limited by the resolution $(0.2 \mu \mathrm{m})$. Therefore, color light metallography can still be considered as a very useful method in comparison to other advanced techniques of microstructural analyses such as XRD, FE-SEM and EBSD.

Table 4. Various phase constituents detected and estimated using different techniques.

\begin{tabular}{|c|c|c|c|c|c|}
\hline Analysis Method & RA (vol.\%) & M (vol.\%) & B (vol.\%) & B/M (vol.\%) & M/RA (vol.\%) \\
\hline Single-step nital $2 \%$ & failed & failed & failed & $91.8( \pm 2.5)$ & $8.2( \pm 2.5)$ \\
\hline Single-step Vilella's reagent & failed & failed & $28.7( \pm 2.5)$ & - & - \\
\hline Single-step Marble's reagent & failed & failed & $66( \pm 2.5)$ & - & $34( \pm 2.5)$ \\
\hline Double-step I & failed & $10( \pm 2.5)$ & $58( \pm 2.5)$ & - & $32( \pm 2.5)$ \\
\hline Double-step II & failed & $11.5( \pm 2.5)$ & $51( \pm 2.5)$ & - & $37.5( \pm 2.5)$ \\
\hline Triple-step & $12.8( \pm 2.5)$ & $15( \pm 2.5)$ & $72.2( \pm 2.5)$ & - & - \\
\hline Quadruple-step & $13.4( \pm 2.5)$ & $18.5( \pm 2.5)$ & $68.1( \pm 2.5)$ & - & - \\
\hline FE-SEM & failed & failed & $63.7( \pm 2)$ & failed & $36.3( \pm 2)$ \\
\hline EBSD & $15.3( \pm 1.5)$ & failed & failed & $84.7( \pm 1.5)$ & - \\
\hline XRD & $18.0( \pm 1)$ & failed & failed & $82.0( \pm 1)$ & - \\
\hline
\end{tabular}

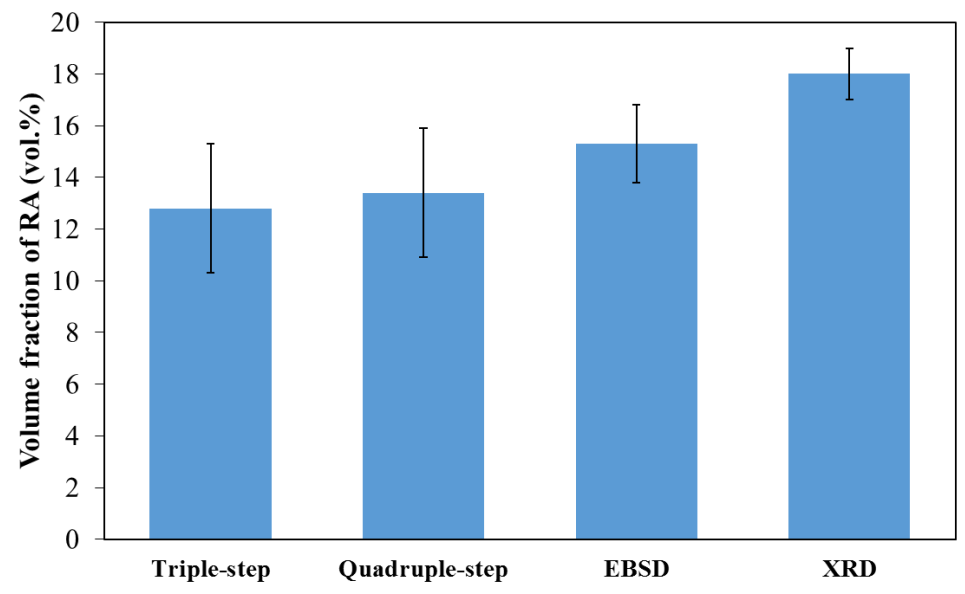

Figure 11. A comparison of the RA volume fractions (vol.\%) estimated using different color light metallography methods: triple-step $(12.8 \%)$ and quadruple-step $(13.4 \%)$. The measurements made using the EBSD (15.3\%) and XRD (18\%) techniques are also included in the figure for comparison. 


\section{Conclusions}

In the present investigation, color metallography was attempted on a high-silicon medium-carbon steel (DIN1.5025) heat treated according to a Q\&B heat treatment. The purpose of this investigation was to detect and identify various microstructural features of the $\mathrm{Q} \& \mathrm{~B}$ sample comprising a mixture of bainite, high-carbon martensite and RA, also present as M/RA phase constituents. Different etching methods were used to distinguish RA phase from martensite and bainite phase constituents in comparison to other advanced techniques of microstructural analyses, such as XRD, FE-SEM and EBSD. The following conclusions can be drawn:

The single-step color metallography method based on general etching with individual reagents, such as $2 \%$ nital or Vilella's solution, or Marble's reagent, was not successful in distinguishing bainite, martensite and RA phase constituents from each other with reasonable contrasting resolution.

Etching with $10 \%$ ammonium persulfate solution followed by Marble's etchant in the double-step method nicely revealed the multiphase microstructures with bainite, martensite and high-carbon M/RA islands appearing as dark gray-, brown- and cream-colored areas, respectively.

Following the triple-step technique using successive etching with $2 \%$ nital, $10 \%$ ammonium persulfate and warm Marble's reagent at $30^{\circ} \mathrm{C}$, the color metallography clearly revealed fine, orange-colored, high-carbon martensite laths present alongside cream-colored retained austenite in M/RA constituents. The bainite plates and martensite laths were also sharply colored as dark gray plates and brown areas, respectively.

A relatively better contrasting resolution was obtained by the quadruple-step etching technique using 2\% nital, 10\% ammonium persulfate, Marble's reagent and warm Klemm's solution $\left(40^{\circ} \mathrm{C}\right)$, thus sharply coloring different phase constituents. This emerged as one of the most effective color metallography techniques.

The multi-step metallography produced a specific thickness of passive film on the surface that resulted in sharp color contrasts for different microstructures, whereas advanced techniques like FE-SEM, EBSD and XRD could not detect individual phases, particularly a distinction between different BCC ferrites.

The volume fraction of RA in the multiphase microstructure of the $Q \& B$ samples was estimated to be about 18 vol.\% by XRD analysis, which is quite reliable. In comparison, the RA estimation using quadruple-step color metallography, which is a relatively simple and inexpensive technique, is lower at $13.34 \mathrm{vol} \%$ because of the resolution limit $(0.2 \mu \mathrm{m})$ and is in good agreement with the EBSD estimate.

Optical microscopy, in comparison to other advanced techniques such as FE-SEM, TEM, EBSD and XRD, is cheaper and commonly used worldwide. In addition, the ease of sample preparation and capability of revealing different phase constituents render it a preferred method for microstructural characterization.

Author Contributions: Conceptualization, S.P.; methodology, S.P.; software, S.S.G.B.; validation, S.S.G.B. and M.S.; formal analysis, S.P.; investigation, F.B. and F.M.; resources, S.P.; data curation, F.B. and F.M.; writing — original draft preparation, S.P, F.B, F.M.; writing—review and editing, F.B., M.S. and J.K.; supervision, project administration, S.S.G.B.; funding acquisition, M.S. and J.K. All authors have read and agreed to the published version of the manuscript.

Funding: This research was funded by the Genome of Steel (Profi3) by the Academy of Finland, grant number 311934.

Data Availability Statement: http:/ /dx.doi.org/10.17632/rjrwm2tt7r.1.

Acknowledgments: The funding of this research activity under the auspices of the Genome of Steel (Profi3) by the Academy of Finland through project \#311934 is gratefully acknowledged. S. Pashangeh expresses her gratitude to the Ministry of Science Research and Technology in Iran for funding a research visit to the University of Oulu, Finland to conduct this research work.

Conflicts of Interest: The authors declare no conflict of interest. 


\section{References}

1. Gao, G.; Zhang, H.; Gui, X.; Luo, P.; Tan, Z.; Bai, B. Enhanced ductility and toughness in an ultrahigh-strength Mn-Si-Cr-C steel: The great potential of ultrafine filmy retained austenite. Acta Mater. 2014, 76, 425-433. [CrossRef]

2. Pashangeh, S.; Somani, M.C.; Ghasemi Banadkouki, S.S.; Karimi Zarchi, H.R.; Kaikkonen, P.; Porter, D.A. On the decomposition of austenite in a high-silicon medium-carbon steel during quenching and isothermal holding above and below the Ms temperature. Mater. Charact. 2020, 162, 110224. [CrossRef]

3. Speer, J.G.; Assunção, F.C.R.; Matlock, D.K.; Edmonds, D.V. The "quenching and partitioning" process: Background and recent progress. Mater. Res. 2005, 8, 417-423, Main Features of Heat Treatment from Intercritical Region, p. 21-23, Effect of Structure on Mechanical Properties of Dual-Phase Steels Contents, p. 71-88. [CrossRef]

4. De Cooman, B.C.; Speer, J.G. Quench and Partitioning Steel: A New AHSS Concept for Automotive Anti Intrusion Applications. steel Res. Int. 2006, 77, 634-640. [CrossRef]

5. Fonstein, N. Advanced high strength sheet steels: Physical metallurgy, design, processing, and properties; Springer: Basel, Switzerland, 2015; ISBN 3319191659.

6. Pashangeh, S.; Zarchi, H.R.K.; Banadkouki, S.S.G.; Somani, M.C. Detection and estimation of retained austenite in a high strength Si-bearing bainite-martensite-retained austenite micro-composite steel after quenching and bainitic holding (Q\&B). Metals 2019, 9, 492. [CrossRef]

7. Wang, Z.; Huang, M.X. Optimising the strength-ductility-toughness combination in ultra-high strength quenching and partitioning steels by tailoring martensite matrix and retained austenite. Int. J. Plast. 2020, 134, 102851. [CrossRef]

8. Li, Y.J.; Kang, J.; Zhang, W.N.; Liu, D.; Wang, X.H.; Yuan, G.; Misra, R.D.K.; Wang, G.D. A novel phase transition behavior during dynamic partitioning and analysis of retained austenite in quenched and partitioned steels. Mater. Sci. Eng. A 2018, 710, 181-191. [CrossRef]

9. Yan, G.; Han, L.; Li, C.; Luo, X.; Gu, J. Characteristic of retained austenite decomposition during tempering and its effect on impact toughness in SA508 Gr.3 steel. J. Nucl. Mater. 2017, 483, 167-175. [CrossRef]

10. Navarro-López, A.; Hidalgo, J.; Sietsma, J.; Santofimia, M.J. Characterization of bainitic/martensitic structures formed in isothermal treatments below the Mstemperature. Mater. Charact. 2017, 128, 248-256. [CrossRef]

11. Pashangeh, S.; Banadkouki, S.S.G.; Somani, M.C. Abnormal mechanical response in a silicon bearing medium carbon low alloy steel following quenching and bainitic holding versus quenching and partitioning treatment. J. Mater. Res. Technol. 2020, 9 , 5007-5023. [CrossRef]

12. Li, W.S.; Gao, H.Y.; Li, Z.Y.; Nakashima, H.; Hata, S.; Tian, W.H. Effect of lower bainite/martensite/retained austenite triplex microstructure on the mechanical properties of a low-carbon steel with quenching and partitioning process. Int. J. Miner. Metall. Mater. 2016, 23, 303-313. [CrossRef]

13. Vander Voort, G.F. Metallography: Principles and Practice; ASM International: Metals Park, OH, USA, 1999; pp. 1-4, ISBN 9780871706720.

14. Vazehrad, S.; Elfsberg, J.; Diószegi, A. Study of microstructure and silicon segregation in cast iron using color etching and electron microprobe analysis. Mater. Charact. 2015, 104, 132-138. [CrossRef]

15. Miley, D.V.; Calabra, A.E. Metallographic Specimen Preparation: Optical and Electron Microscopy; Springer: New York, NY, USA, 1974; pp. 95-115, ISBN 9781461587101.

16. Ghasemi Banadkouki, S.S.; Mehranfar, S.; Karimi Zarchi, H.R. Effect of Cu addition on hardness and microstructural features of low alloy white cast iron. Mater. Res. Express 2019, 6, 026547. [CrossRef]

17. Zhao, H.S.; Zhu, X.; Li, W.; Jin, X.J.; Wang, L.; Jiao, H.; Jiang, D.M. Austenite stability for quenching and partitioning treated steel revealed by colour tint-etching method. Mater. Sci. Technol. 2014, 30, 1008-1013. [CrossRef]

18. Vander, G.F.; Buehler, V.; Bluff, L. Martensite and Retained Austenite. Mater. Charact. Test. 2009, 76, 51-54.

19. Novy, Z.; Uhlir, J.; Janovec, J.; Kusy, M. Evaluation of Retained Austenite in High Strength Steels. In Proceedings of the International Conference New Developments Applications of High Strength Steels, Buenos Aires, Argentina, $26-28$ May 2008.

20. Xie, Z.J.; Liu, Z.F.; Misra, R.D.K.; Shang, C.J.; Han, G.; Wang, X.L. Retained austenite stabilisation in low carbon high silicon steel during isothermal holding. Mater. Sci. Technol. 2019, 35, 45-54. [CrossRef]

21. Vander Voort, G. Color metallography Vol. 9 ASM handbook. Metallogr. Microstruct. 2004, 493-512.

22. Walker, P.; Tarn, W.H. CRC Handbook of Metal Etchants; CRC Press: Boca Raton, FL, USA, 1990; pp. 70-75. ISBN 0849336236.

23. Girault, E.; Jacques, P.; Harlet, P.; Mols, K.; Van Humbeeck, J.; Aernoudt, E.; Delannay, F. Metallographic Methods for Revealing the Multiphase Microstructure of TRIP-Assisted Steels. Mater. Charact. 1998, 40, 111-118. [CrossRef]

24. Li, H. Microstructure and Mechanical Properties of $50 \mathrm{SiMnNiNb}$ Steel by a Novel Quenching-Partitioning-Austempering Heat Treatment. Chin. J. Mech. Eng. 2009, 22, 645-650. [CrossRef]

25. Standard Guide for Preparation of Metallographic Specimens. Am. Soc. Test. Mater. 2001, 3, 1-7.

26. ASTM E562. Standard Test Method for Determining Volume Fraction by Systematic Manual Point Cloud; ASTM International: West Conshohocken, PA, USA, 2019.

27. ASTM. Standard Practice for X-Ray Determination of Retained Austenite in Steel with Near Random Crystallographic Orientation 1. 2009. Available online: https://www.astm.org/Standards/E975 (accessed on 23 May 2021).

28. Vander Voort, G.F.; Manilova, E.P.; Michael, J.R. A study of selective etching of carbides in steel. Microsc. Microanal. 2004, 10, 76-77. [CrossRef] 
29. De Castro, M.; Martín Álvarez, Y.; Moreno-Labella, J.J.; Panizo-Laiz, M.; del Río, B. Color-Metallographic Characterization of Alloyed White Cast Irons Ni-Hard Type. Metals 2020, 10, 728. [CrossRef]

30. Gourgues-Lorenzon, A.F. Application of electron backscatter diffraction to the study of phase transformations. Int. Mater. Rev. 2007, 52, 65-128. [CrossRef]

31. Zhao, H.; Wynne, B.P.; Palmiere, E.J. A phase quantification method based on EBSD data for a continuously cooled microalloyed steel. Mater. Charact. 2017, 123, 339-348. [CrossRef]

32. Zhang, Y.; Lai, P.; Jia, H.; Ju, X.; Cui, G. Investigation of Test Parameters on EBSD Analysis of Retained Austenite in TRIP and Pipeline Steels. Metals 2019, 9, 94. [CrossRef]

33. Witte, M.; Lesch, C. On the improvement of measurement accuracy of retained austenite in steel with X-ray diffraction. Mater. Charact. 2018, 139, 111-115. [CrossRef] 